\title{
Language in ageing persons with Down syndrome
}

\author{
Jean A. Rondal and Annick Comblain \\ Laboratoire de Psycholinguistique, University of Liege, Belgium
}

\begin{abstract}
Several cross-sectional studies and one longitudinal study were conducted on the language abilities of various cohorts of persons with Down syndrome aged between 14 and 50 years. No significant difference was observed on any of the receptive and productive morphosyntactic and lexical measures used, suggesting no marked change in the language of these persons from adolescence onto late adulthood. Repeated measures of cerebral metabolic rate (CMR) for fluorodeoxyglucose using a Positron Emission Tomography were made over a 4-year interval with 7 participants with Down syndrome aged between 37 and 49 years. A gradual decrease in global CMR for both cerebral hemispheres and for each participant was documented. It was particularly marked for 3 participants. However, no language deterioration could be associated with their marked lowering in CMR.
\end{abstract}

Keywords - Ageing, Alzheimer disease, cerebral imagery, Down syndrome, language

\section{Down syndrome and Alzheimer disease}

People with Down syndrome live very much longer lives now than was the case before the 1950s. According to Baird and Sadovnick (1995; data confirmed in other studies regarding various countries, e.g. Dupont, Vaeth, \& Videbech, 1986; Jancar \& Jancar, 1996), life expectancies beyond 68 years for over 15 percent and 55 years for over 50 percent of individuals with Down syndrome are now common. Strauss and Eyman (1996) estimate the life expectancy in people with Down syndrome to be around 55 years on average. Further progress may probably still be expected. It is predicted that between the years 2000 and 2025, the number of adults with Down syndrome will double. Beyond that point in time, the prevalence of people with Down syndrome in our societies will largely depend on the response of present-day and future parents of babies with Down syndrome to the availability of earlier detection of the condition and so-called therapeutic abortive practices.

These gains in longevity have brought about increased interest in adults and ageing in people with Down syndrome. About three decades ago the possibility of a marked susceptibility of individuals with Down syndrome to a degenerative condition known as Alzheimer disease, was signalled, as well as a tendency towards earlier physiological and neuropsychological ageing in comparison with the typical population and people with learning difficulties with other aetiologies. It has been suggested that beyond
35-40 years most if not all individuals with Down syndrome would develop a form of Alzheimer disease leading to major debilitation and the loss of most of the skills acquired earlier in life.

Recent work has softened this dark prognosis. It is admitted now (e.g. Wisniewski \& Silverman, 1999) that trisomy 21 does not necessarily carry the unavoidable destiny of progressive deterioration during middle age. There is no question, however, that there exists an elevated risk of Alzheimer disease or Alzheimer-like disease (Alzheimer disease is not actually a single disease but a complex of related diseases) in Down syndrome (between 25 and $45 \%$ beyond 55 years; Zigman, Schup, Haaveman, \& Silverman, 1997). Neurological examination of the brains of individuals with Down syndrome who died over the age of 30 years reveals that pathological changes associated with Alzheimer disease (e.g. brain atrophy, nerve cell loss, neurotransmitter changes, senile plaques, and neurofibrillary tangles Mann, 1992) have taken place in the amygdala, hippocampus, and the frontal, temporal, and parietal cortices (cf. Holland \& Oliver, 1996, for a review). However, for those individuals with Down syndrome who develop Alzheimer disease, there may be a 10 -year latency period (in opposition to the usual 4 or 5 years in the typical population; Wisniewski \& Silverman, 1999) between the presence of important Alzheimer disease-type neuropathological changes, appearing around 30-35 years, and clinical dementia which may remain undetectable in many adults with Down syndrome up to 30 years later (Wisniewski \& Silverman, 1996). 
A limited number of studies have focused on cerebral metabolism in older individuals with Down syndrome. Schapiro et al. (1987) measured the cerebral metabolic rate for glucose (CMRG; 18F2 -fluoro- 2 deoxydextroglucose) in cohorts of typically developing individuals and those with Down syndrome, aged between 19 and 64 years. Mean hemispheric CMRG was lower in the older than in the younger participants with Down syndrome (and, as a rule, lower in Down syndrome than in typical participants). Only some older individuals with Down syndrome were clinically demented even if age related reductions in neurological variables seemed to occur in most of them. In another cerebral metabolic study, however, Schapiro, Haxby and Grady (1992) found similar CMRG in non-demented individuals with Down syndrome over 35 years of age and typical controls. Similar results were found by Dani et al. (1996). In contrast, Deb, de Silva, Gemmel, Besson, Smith, and Ebmeier (1992) reported cerebral metabolic rates in seven older individuals with Down syndrome comparable to those of younger individuals with Down syndrome and slightly diminished rates (particularly in the posterior parietotemporal and occipital zones) in nine other non-demented older participants with Down syndrome.

The above findings must be put in context. Developments in histopathological approaches to dementia suggest that age is probably not the sole and may not even be the primary cause of senile dementia (Brion \& Plas, 1987). Moreover, and particularly important for people with Down syndrome often exposed to a less stimulating environment later in life, aged individuals may suffer from (treatable) pseudodementias (often misdiagnosed depressive states) (also Campbell-Taylor, 1993; Florez, 1993, 2000).

\section{Earlier neuropsychological decline}

The question remains, however, of an earlier onset of neuropsychological decline in adults with Down syndrome not related to the onset of Alzheimer disease in most individuals (Brown, 1985), but more marked than in individuals with learning disabilities with aetiologies other than Down syndrome (Thompson, 1999). The predisposition towards earlier ageing in Down syndrome may be asso- ciated with the overexpression of genes located on chromosome 21, distinct from the gene coding for amyloid preprotein (residing in the proximal part of the long arm of chromosome 21 and supplying one key factor in Alzheimer disease neuropathology). Similarly, the clinical phenotype of Down syndrome could be modulated by genes on chromosomes other than chromosome 21 (Royston, Mann, Pickering-Brown, \& Owen, 1994), but these genes remain to be identified (Wisniewski \& Silverman, 1996). Research is needed to assess the abilities of people with Down syndrome in their forties and beyond, and possible declines in their neuropsychological functioning should be measured.

\section{Language in adults with Down syndrome}

My coworkers and I have collected series of data relevant to the above problems, particularly regarding language (Comblain, 1996; Rondal \& Comblain, 1996; George, Thewis, Van der Linden, Salmon, \& Rondal, 1999; submitted for publication). The same instrument for analysing morphosyntactic aspects of language (BEMS; Batterie pour 
l'Evaluation de la Morpho-Syntaxe; Comblain, 1995) was used with cohorts of individuals with Down syndrome of different chronological ages (CA) allowing cross-sectional comparisons. Each group included seven participants (four females and three males). They were compared on the receptive sub-tests of the BEMS, i.e. nominal coreference in the case of personal pronouns, definite and indefinite articles, temporal morphological inflections, negative sentences, reversible and nonreversible passives sentences, sentences with coordinate clauses, sentences with temporal, causal, conditional, or consequential subordinate clauses, and sentences with relative subordinates in qui (grammatical subject) or que (direct grammatical object). Table 1 lists the characteristics of the three CA samples of participants with Down syndrome (comparison 1). Table 2 displays the group means and standard deviations for the eight sub-tests of the BEMS.

A one-way MANOVA for non-repeated measures was carried out simultaneously on the eight dependent variables for the three CA groups. It is not advisable to analyse multivariate data in an ANOVA on each variable separately, particularly when the number of variables and the proportion of variance that these variables have in common increase together (Hummel \& Sligo, 1971). In such cases, the experimental error rates, i.e. the probability that at least one comparison will be declared significant when, actually, the null hypothesis is true for all comparisons, increases to an unknown level. This and the fact that the errors tend to occur in sets can easily allow misinterpretation of the findings. The threshold level for statistical significance was set at $p<.05$. The distribution used to test the significance of the multivariate effects was based on approximation of the Wilk's Lambda distribution to an F distribution. The observed values of the Wilk's Lambda and the Rao R form 2, were respectively: .09 and .33 ; yielding a probability of wrongly rejecting the null hypothesis of .92 .

In the above analysis, the statistics of the dependent variables have dichotomous (zero-one type) distributions. This is also the case for a large number of the data used later in the report. This violates one of the assumptions underlying the $\mathrm{F}$ test in the analysis of variance (namely, the necessity for the distribution in each population to be normal; a dichotomous variable by definition is not normally distributed; it needs not even be a continuous variable). However, Lunney (1970) has shown that the analysis of variance is an appropriate statistical technique for analysing dichotomous data in fixed effects models where cell frequencies are equal under the condition that the proportion of responses in the smaller dichotomous response category is equal or greater than .2 and there are at least 20 degrees of freedom for error, which was the case in the results of the present investigation.

As comparison 1 reveals, there is no difference in the receptive morphosyntactic functioning of individuals with Down syndrome from adolescence to mature adulthood, i.e. over an interval of time of 32 years in our studies. Regarding language production, no direct comparison of the younger and the older adults was possible because, on this occasion, the same set of language production measures was not used for comparing the adolescent and the younger adult groups (this data was actually collected in two separate studies). See below, in comparison 2, for the productive measures used. The paper by Rondal and Comblain (1996) contains the data resulting from the comparison of the same adolescents and younger adults with Down syndrome as in the present report. Accordingly, no significant change was observed as to mean length of utterance (MLU) - a valid if global index of expressive morphosyntax - and to the expressive referential lexicon (TVAP: Test de Vocabulaire Actif et Passif; TVP: Test de Vocabulaire Productif). Although we do not have specific data at hand to support our conclusion, it is unlikely that marked changes in productive language would take place in the period between thirty and forty years of age in people with Down syndrome, particularly given that no significant change has been documented in the receptive abilities of the same individuals with Down syndrome and that no significant productive or receptive change has been revealed either by our analyses of the language of persons with Down syndrome between forty and fifty years (see below).

As we indicated in a review of the specialised literature (cf. Rondal \& Comblain, 1996), significant language progress does not take place, at least in phonological and the grammatical aspects, beyond mid-adolescence. As we also noted, progress may still be observed beyond that age in the conceptual and the pragmatic aspects of language (e.g. vocabulary, conversational and more generally communicative, abilities, and discourse organisation). This supports the necessity to distinguish between language components in these types of analyses. There are a few ambiguous suggestions and claims in the recent literature regarding "continuing" language development in late adolescence and early adulthood. Chapman (1999), for example, has documented progress over time (until 20 years CA; cross-sectional study design) in the discourse narratives of some individuals in a group of participants with Down syndrome. From there, she refutes the maturational hypothesis proposed by Lenneberg (1967) and Fowler (1990), according to which no marked language improvement is possible beyond early adolescence. This may be a case of using correct data to derive an improper conclusion. Lenneberg and Fowler's characterisations may indeed not be fully appropriate. The word language creates problems in their statements as well as in those of Chapman. We have suggested and justified (cf. Rondal \& Edwards, 1997) that it makes more empirical sense to restrict maturational susceptibility to the formal components of language, i.e. phonology and grammar. Chapman's data apparently contradicting the maturational hypothesis, are actually compatible with such a modified conception. 


\section{A four-year study}

We have also conducted a four-year longitudinal study with 12 participants with Down syndrome aged between 37 and 49 years (six women and six men). Language functions (receptive as well as productive) were assessed for all participants at one year intervals during the first two years. Four individuals did not maintain their participation beyond the second year. For the others, the study was continued for another two years using the same evaluation procedure. For eight participants (four women and four men) a measure of cerebral metabolic rate (CMR) for fluorodeoxyglucose (18FDG) was made every year using PET (positron emission tomography) technique which produced 31 reconstructed plans from the scans (cf. George et al., 1999, for more technical details). For seven of these eight participants (one female died in the meantime), the cerebral imagery investigation was continued for two more years with one examination taking place every year.

\begin{tabular}{|c|c|c|c|c|}
\hline \multirow[b]{2}{*}{ RECEPTIVE TASKS } & \multicolumn{4}{|c|}{ DOWN SYNDROME PARTICIPANTS / TIME } \\
\hline & $\mathbf{I}$ & 2 & 3 & 4 \\
\hline \multicolumn{5}{|l|}{ BEMS } \\
\hline I. Nominal coreference & $5 \mathrm{I}(15)$ & $29(9)$ & $39(17)$ & $40(15)$ \\
\hline 2. Articles & $36(17)$ & $23(7)$ & $27(\mathrm{II})$ & $28(16)$ \\
\hline 3. Temporal inflections & $40(15)$ & $35(8)$ & $32(10)$ & $34(7)$ \\
\hline 4. Negatives & $36(35)$ & $45(35)$ & $34(29)$ & $30(20)$ \\
\hline 5. Passives & $52(29)$ & $48(18)$ & $43(10)$ & $36(2 I)$ \\
\hline 6. Coordinates & $64(27)$ & $48(26)$ & $50(13)$ & $57(10)$ \\
\hline 7. Subordinates & $51(20)$ & $47(14)$ & $39(13)$ & $37(15)$ \\
\hline 8. Relatives & $73(18)$ & $68(10)$ & $55(12)$ & $46(14)$ \\
\hline Lexical designation ${ }^{2}$ & $19(5)$ & $18(5)$ & $19(5)$ & $20(5)$ \\
\hline \multicolumn{5}{|l|}{ PRODUCTIVE TASKS } \\
\hline Verbal fluency & $10(5)$ & $9(4)$ & $8(3)$ & $8(3)$ \\
\hline \multicolumn{5}{|l|}{ Lexical labelling } \\
\hline TOTAL $^{3}$ & $144(17)$ & $137(33)$ & $135(28)$ & $137(33)$ \\
\hline Fruits & $25(6)$ & $24(4)$ & $23(5)$ & $25(9)$ \\
\hline Clothes & $28(5)$ & $26(5)$ & $28(4)$ & $27(6)$ \\
\hline Vegetables & $25(\mathrm{II})$ & $24(8)$ & $21(8)$ & $21(6)$ \\
\hline Kitchen tools \& objects & $33(4)$ & $31(8)$ & $30(8)$ & $32(6)$ \\
\hline Animals & $33(9)$ & $31(12)$ & $33(10)$ & $31(I I)$ \\
\hline \multicolumn{5}{|c|}{ Narrative text about pictures (verbal recall) } \\
\hline Ideas $^{4}$ & $3(1)$ & $3(I)$ & $2(2)$ & $3(2)$ \\
\hline Words $^{5}$ & $10(4)$ & $10(6)$ & $7(5)$ & $8(6)$ \\
\hline Report (morphosyntactic & $25(13)$ & $28(15)$ & $28(20)$ & $23(13)$ \\
\hline \& semantic aspects) ${ }^{6}$ & & & & \\
\hline
\end{tabular}

Table 3. Group means and standard deviations from the receptive and the productive tasks in older DS adults at one year interval during four years (comparison 2)'.

Notes: '. BEMS Data are expressed in percent of correct responses. Other data are raw scores of correct responses. Standard deviations are given in parentheses; ${ }^{2}$. Maximum correct score is 40; 3. Maximum correct score is 254 ; maximum correct scores for the semantic categories: fruits, 56 , clothes, 48, vegetables, 46, kitchen tools \& objects, 52, and animals, 52; ${ }^{4}$ Each global idea from the original story correctly recalled was worth .5 point; ${ }^{5}$. Number of words per utterances in the story recall; ${ }^{6}$. Global index integrating separate scores for the use of causal relations, anaphoric pronouns replacing thematic nouns functioning as sentence subjects, the correct working of chronology in the story, the production of complex sentences, and the number of tenses used in the story recall (maximum note 100).
For the sake of statistical consistency, the quantitative analyses were carried out taking only the seven participants who made it through the 4 years of the study into account. 3 displays the group means and standard deviations adults with Down syndrome. The BEMS was used to assess ceptive morphosyntax. A receptive lexical task (picture fluency was used to test productive language. Participants ere requested to supply orally the largest possible number anes during a period of one minute. An origin lexical labelling (picture denomination) was administered. It consisted of 127 items divided into five semantic categories (fruit, clothes, vegetables, kitchen tools objects, and animals). The phonetic length of the items was controlled (items of 1,2 , or 3 syllable long were presented) as well as the frequency of appearance of these items in language (frequency tables for the French language established by the Laboratory of Experiment Psychology at the Free University of Brussels). The participants were allowed 20 seconds for answering. After this time, phonemic help was offered (the first phoneme of the target word was supplied by the examiner). In case of further error or absence of response, syllabic help was given (the first syllable of the target word was produced by the examiner). The aim was to separate a possible word finding difficulty from a genuine ignorance of the target name. Lastly, the test "Récit sur images" (Narrative text about pictures; verbal recall, adapted from ChevrieMüller, 1981), was administered. This test takes into account the number of global ideas, words, and several formal and semantic characteristics of the narratives as they are freely recalled by the participants.

A one-way (4 age levels) MANOVA for repeated measures was carried out simultaneously on the eight dependent variables from the BEMS. The observed values of the Wilk's Lambda and the Rao R form 2 were, respectively: .26 and 1.22 , yielding a $p$ of .27. A one-way (4 age levels) univariate ANOVA for repeated measures was performed on the scores for lexical 
designation. The $F$-value obtained was .26, yielding a $p$ of .85. Similarly the one-way (4 age levels) ANOVA for repeated measures performed on the verbal fluency data failed to reveal any significant age effect $(F=.36, p=.78)$. A one-way (4 age levels) MANOVA for repeated measures was carried out simultaneously on the five dependent variables (semantic categories) of the test of lexical labelling. The observed values of the Wilk's Lambda and the Rao R form 2 were, respectively: .81 and .29 , yielding a nonsignificant $p$-value of .99 . A one-way ( 4 age levels) univariate ANOVA for repeated measures was carried out on the total denomination scores also yielding a nonsignificant $F$-value $(F=.14, p=.94)$. Neither the syllabic length of the lexical items nor their relative frequency in the French language seemed to matter regarding the lexical labelling scores of the adults with Down syndrome (nonsignificant MANOVA scores). The phonological as well as the syllabic aids supplied by the examiners did not influence the labelling scores at any age (the mean number of correct labelling produced by the participants with Down syndrome in response to these two probes were around 1.50 (standard deviation around 2 ) for the results at times 1 and 2 and less (nonsignificantly so) at times 3 and 4 . This is suggestive of the fact that the labelling scores obtained by the adults with Down syndrome did indeed reflect their lexical knowledge and not a word finding difficulty as often observed in participants with preclinical Alzheimer disease.

Turning to the CMR data. The left and right frontal, parietal, and temporal cortices of each participant were examined and the visual metabolic images from the associative cortical regions were evaluated in a semi-quantitative way on a scale from zero (normal metabolism) to two (severe metabolic reduction) (Hoffman et al., 1996; Pickut et al., 1997). As expected, no CMR image was normal by any strict definition in any participant with Down syndrome and there was a large interindividual variability. Globally, metabolic reduction was more marked in the left hemisphere. There is a gradual decrease in global CMR for both cerebral hemispheres and for each of the seven individuals with Down syndrome (average global CMR for the right hemisphere at times 1 and 3 , respectively 1.57 and 3.58 ; average global CMR for the left hemisphere at times 1 and 3 , respectively 2.50 and 5.50 ). The average decreases, however, are largely due to three participants. Analysing the individual performance of these three participants in the language tasks over the same interval of time, no deterioration indication emerges that could be meaningfully related to the lowering in CMR. It is possible that global brain metabolism (particularly within the left cerebral hemisphere) is diminishing substantially in some of our participants with Down syndrome without, at least temporarily, any clear negative consequences on language, and more general cognitive functions. ${ }^{1}$

\section{Discussion}

As our data shows that no significant change takes place in the language of individuals with Down syndrome in the interval of time between late adolescence and fifty years of age. This is worth noting as functional modifications of language and memory have often been indicated as first signs of earlier ageing and degenerative diseases. Jodar (1992), for example, has suggested that in normal ageing, lexical and verbal comprehension in general are preserved whereas verbal fluency, lexical labelling, and, more generally, the capacity for verbal production tend to decline. It is interesting that in a cross-sectional study with 44 Italian individuals with Down syndrome $(25$ males and 19 females) ranging in age from 14 to 43 years and 7 months (average CA 26 years 9 months), centred on an investigation of visual-perceptual abilities (using the Frostig Developmental Test of Visual Perception -DTVP- Frostig, Maslow, Lefever, \& Whittlesy, 1963) and adaptive behaviour (using an Italian adaptation - Pedrabissi \& Soresi, 1989- of the Adaptive Behavior Inventory of Brown and Leigh, 1986). Saviolo-Negrin, Soresi, Baccichetti, Pozzan, and Trevisan (1990) reported no significant age difference

1. The reports by George, Thewis, Van der Linden, Salmon and Rondal (1999, submitted for publication) contain the results of corresponding investigations carried out with the same adult participants with Down syndrome on a number of major cognitive functions (general behavioural and cognitive abilities - using a French-language adaptation of the Dementia Questionnaire for Mentally Retarded Persons, of Evenhuis, Kengen, and Eurlings, 1990; the Batterie pour l'Examen Psychologique de l'Enfant - evaluating a large range of cognitive functions including memory, lexicon, visual perception and hand movements, and adapted in French from the K-ABC of Kaufman and Kaufman, 1993; working memory, visuospatial as well as auditory-vocal, episodic memory, retrospective and prospective memory - using a modified version of the Children's Version of the Rivermead Behavioural Memory Test, RBMT-C, of Wilson, IvaniChalian, and Aldrich, 1991 - and attention - using the Barcelona Test of Péna-Casanova, 1990). These results will not be presented here. It is worth briefly mentioning, however, that no significant differences were observed between the results obtained from the adults with Down syndrome at time 1 and time 4, for any of the cognitive functions examined, except for a statistically significant difference suggesting a slight decrease in the extent of the visuo-spatial working memory span and in the digit span of the K-ABC Test; these two deterioration effects on an already quite low baseline as is most often characteristic of present-day adults with Down syndrome. As for the language data, no cognitive indication could be meaningfully related to lowered CMR between time 1 and time 4 in the three adults with Down syndrome for whom such a CMR lowering was observed. Lastly, George et al.'s (1999) report also mentions a cross-sectional comparison between the 7 older adults with Down syndrome studied here at time 1 and a group of 15 younger adults with Down syndrome (chronological ages between 20 and 35 years), bearing on the performance in working memory (visuo-spatial as well as auditory-vocal), episodic memory, and retrospective and prospective memory (again based on a modified children's version of the Rivermead Behavioural Memory Test - RBMT-C). No significant difference was observed on any comparison between the two cohorts of participants (regarding the RBMT, George et al.'s finding is in agreement with Wilson and Ivani-Chalian, 1995, reporting no significant difference on the same RBMT-C in a group of 37 adults with Down syndrome aged 19 to 44 years, controlled for chronological age). These data are supportive of an interpretative hypothesis according to which no major change in basic cognitive functioning takes place from early adulthood to 45 years and later in many or most individuals with Down syndrome. 
in their participants with Down syndrome regarding adaptive behaviour but a significant, even if limited, decline in visual perception beyond 25 years of age, except in the visual-motor sub-test of the DTVP.

What may be happening after about fifty years in individuals with Down syndrome is unknown at present because of the lack of systematic data. Hints may be derived from the limited literature in existence pending verification through more extensive studies. Little or no change in nonverbal reasoning, memory, language (receptive and expressive vocabulary), planning and attention, perceptual-motor, and adaptive skills, have been recorded until up to sixty years in a study by Das, Divis, Alexander, Parrila, and Naglieri (1995). However, Das et al. (1995) state that the older participants with Down syndrome in their cohorts (i.e. those slightly beyond 60 years) were actually performing more poorly than those in younger groups particularly in tasks requiring planning and attention. This could perhaps be compared with the observation of Ribes and Sanuy (2000) of a slight decline in expressive language (particularly vocabulary) in some of their participants with Down syndrome beyond 38 years, and with Prasher's (1996) suggestion regarding the existence of age-associated functional decline in approximately $20 \%$ of the people with Down syndrome aged 50 to 71 years, in short-term memory, speech, practical skills, activity, and general interests.

Cross-sectional studies are of course limited in their ability to demonstrate time changes as they compare different participants at different ages mixing together interindividual and age-related variances. Regarding Down syndrome, the problem is complicated by a cohort difference: i.e. younger participants with Down syndrome have generally been the targets of early cognitive intervention (at least in the developed countries) whereas older people with Down syndrome have not. It could be hypothesised that early intervention has the potential effect of upgrading development in many individuals with Down syndrome therefore rendering the comparisons with older cohorts of people with Down syndrome difficult or even invalid. A few longitudinal studies have been conducted. Devenny, Hill, Patxot, Silverman and Wisniewski (1992) and Burt, Loveland, Chen, Chuang, Lewis and Cherry (1995) did not observe significant changes in the cognitive functioning of individuals with Down syndrome aged between 27 and 55 years and 22 and 56 years in the two studies, over intervals of time ranging from 3 to 5 years. Devenny, Silverman, Hill, Jenkins, Sersen and Wisniewski (1996) report only four cases of cognitive decline in 91 individuals with Down syndrome followed for several years beyond the age of fifty years.

The above observations do not suggest a rapid and marked age-related decline in cognitive and language functioning in participants with Down syndrome beyond the age of 50 years, apart from the episodic occurrence of progressive dementia.
An interesting piece of research that has come to our attention may be added to the present discussion. About ten years ago, the first author found himself in a position to analyse the language and cognitive level of a woman with Down syndrome, named Françoise, presenting exceptional language abilities for a person with Down syndrome (cf. Rondal, 1995, for the complete report). Recently, the daycentre where Françoise (now aged 45) spends several days a week requested a neuropsychological examination because of her depressed behaviour, lack of initiative and possible memory losses. Dr. Michel Ylieff, a neuropsychologist from the University of Liège, who specialises in the clinical/ psychological aspects of ageing, agreed to carry out a reexamination of some of Françoise's cognitive functions. Thanks to M. Ylieff's courtesy, we are in possession of the confidential report summarising the results of this examination (dated May 2000a). Comparing his data with those of Rondal (1995), Ylieff reports a marked decline of Françoise's episodic memory and ability to deal with visuo-spatial and graphic material. Pending further neurological and neuroradiological examinations, Ylieff suggests the possibility of localised pathology of the right cerebral hemisphere possibly linked with incipient brain degeneration. In the last case, the first clinical expression reflects less well-developed cognitive domains, in the case of Françoise, spatial functions. Regarding oral language, only one labelling test was administered by Ylieff, (The Test de dénomination of Bachy - 36 items). It yielded a global score for Françoise closely corresponding to the estimated typical population mean for this test. No morphosyntactic evaluation was attempted. Based on the three encounters with Françoise needed to complete the testing and including informal conversations with her, Ylieff's impression (Ylieff, 2000 b) was that Françoise's overall language was intact in as much as could be assessed, which is also the opinion of the staff of the day-centre attended by Françoise. At the age of 45, therefore, no major decline in Françoise's functional language seems to be occurring, even if she may be experiencing additional difficulties in her already weaker other mental functions as a consequence of a possible accelerating ageing or degenerative process.
I. Slower receptive and productive language processing.

2. Less efficient respiratory support for speech.

3. Aggravated hearing problems and reduced attention to auditory stimuli; difficulties in perceiving low voiced and whispered speech, speech in noisy conditions, and in communicating on the telephone.

4. Additional difficulties in linguistic analysis particularly with less frequent and/or more complex syntactic structures.

5. Additional difficulties in planning, producing or monitoring information in longer spoken discourse.

6. Augmented rates of dysfluencies (hesitation pauses, fillers, and interjections).

7. Reduced word fluency.

8. Increased difficulty in oral word discrimination, and in retrieving infrequently used common and (even more) proper nouns.

Table 4. Frequent speech and language difficulties in ageing persons (after Rondal \& Edwards, 1997). 
For those people with Down syndrome developing Alzheimer disease, the exact pattern of language decline has not yet been specified. In typically developing individuals, the language changes which are most apparent at first are at the semantic level, particularly in the reduction of available vocabulary and breakdown of semantic associations (Martin, 1987). Difficulty in word finding is one of the most noticeable features of preclinical Alzheimer disease. Auditory comprehension of words also becomes deficient, as does the processing of semantic complexity in sentences and paragraphs (Hart, 1988). Additionally, the quality of discourse, its cohesion, and, in short, the whole pragmatics of language are gravely deteriorating (Maxim \& Bryan, 1994).

Interesting is the repeated observation that the grammatical aspects of language are largely spared in the early stages of Alzheimer disease (Appel, Kertesy, \& Fishman, 1982; Kempler, Curtiss, \& Jackson, 1987; Murillo Ruiz, 1999). Grammar is eventually degraded together with the progressive breakdown of conceptual aspects of language and the complete collapse of pragmatic regulation (Maxim \& Bryan, 1994).

There is no logical reason why the fate of language of people with Down syndrome and Alzheimer disease should be any different from that of people who do not have Down syndrome. Accordingly, predicted language profiles associated with individuals with Alzheimer disease and Down syndrome in the first stages of the disease would be characterised by major dissociations between morphosyntax, on the one hand, and language semantic and pragmatic aspects, on the other hand. The former aspects are underdeveloped in typical individuals with Down syndrome and they would be little affected as a direct result of subclinical Alzheimer disease. The latter language aspects will be found to be deteriorating to a varying extent between people with Down syndrome.

There seems to exist a susceptibility in individuals with Down syndrome for ageing (biologically as well as psychologically) one or two decades in advance of a control population (Vicari, Nocentini, \& Caltagirone, 1994). The exact causes for this decline are not known. The same decline as in healthy older people without learning disabilities could be the same as in people with Down syndrome but occurring earlier in life. Regarding language, frequent speech and language problems encountered in later life by individuals from the typical population are listed in Table 4. It is possible that for individuals with Down syndrome the effect of ageing (as well as that of subclinical Alzheimer disease) would be particularly clear at first in those areas already of greater weakness (individually or syndromically).

\section{Language maintenance}

Language therapy, or better language maintenance, with the elderly from the wider population (e.g. Maxim \& Bryan, 1994) could be adapted for ageing individuals with Down syndrome. It could help to reduce their processing difficulties. Also the social environments of ageing people with learning disabilities should be organised to take the language limitations of these people more into account (e.g. speaking more slowly and loudly, using shorter and simpler utterances, reducing the effects of background noise, allowing additional time for processing incoming language and responding, arranging settings, seatings, lighting, to encourage social proximity and communication rather than to limit it, etc.).

Speech and language therapy for elderly people with learning disabilities is a slowly developing speciality which certainly requires the evaluation of its effectiveness and probably more specific training. The cost of providing monitoring, continued support, and maintenance training for elderly people with learning disabilities is no doubt significant. However, such programs would certainly prove cost-effective in terms of keeping people with learning disabilities better functioning for longer periods of time and therefore saving on the cost of institutional care, as well as markedly reducing psychological stress in families and carers.

In conclusion, it is not enough for advanced societies to integrate individuals with learning disabilities better and more openly into their open fabric. More systematic efforts ought to be directed to setting the contexts permitting these persons to enjoy fuller and more rewarding lifestyles during the later part of their lives.

\section{Acknowledgement}

Parts of this research were sponsored by the Belgian National Board for Scientific Research (Fonds National de la Recherche Fondamentale et Collective, Convention 2.4535.95F, 1995-1999). This paper is based on a keynote presentation made at the 3rd International Conference on Language and Cognitive Development in Down syndrome, Portsmouth, UK, September 2000.

\section{Correspondence}

Jean A. Rondal • Laboratoire de Psycholinguistique, Université de Liege, Bd. du Rectorat, 5, Bat, B.32, Sart Tilman 4000, Liege, Belgium. • Email: JA.Rondal@ulg.ac.be

\section{References}

Appel, J., Kertesz, A., \& Fishman, M. (1982). A study of language functioning in Alzheimer's patients. Brain and Language, 17, 73-91.

Baird, P., \& Sadovnick, A. (1995). Life expectancy in Down syndrome. Lancet, 2, 1354-1356.

Bishop, D., \& Byng, S. (1984). Accessing semantic comprehension: Methodological considerations and a new clinical test. Cognitive Neuropsychology, 1, 223-243.

Brion, S., \& Plas, J. (1987). Etat actuel de l'approche histopathologique des démences. Psychologie Médicale, 19, 1235-1242.

Brown, W. (1985). Genetics of aging. In M. Janicki \& H. Wisniewski (Eds.), Aging and Developmental Disabilities: Issues and Approaches (pp. 185-194). Baltimore, MD: Brookes. 
Brown, L., \& Leigh, J. (1986). Adaptive Behavior Inventory $A B I$. Austin, TX: Pro-Ed.

Burt, D., Loveland, K., Chen, Y.-W, Chuang, A., Lewis, K., \& Cherry, L. (1995). Aging in adults with Down syndrome: Report from a longitudinal study. American Journal of Mental Retardation, 100, 262-270.

Campbell-Taylor, I. (1993). Communication impairments in Alzheimer disease and Down syndrome. In J. Berg, H. Karlinsky, \& A. Holland (Eds.), Alzheimer Disease, Down Syndrome and their Relationship (pp.175-193). New York: Oxford University Press.

Chapman, R. (1999). Language development in children and adolescents with Down syndrome. In J. Miller, M. Leddy, \& L. Leavitt (Eds.), Improving the Communication of People with Down Syndrome (pp. 41-60). Baltimore, MD: Brookes.

Chevrie-Müller, V. (1981). Epreuves pour l'Examen du Langage: Batterie Composite. Paris: Editions du Centre.

Comblain, A. (1995). Batterie pour l'Evaluation de la Morpho-Syntaxe. Liège: Laboratoire de Psycholinguistique de l'Université de Liège (unpublished).

Comblain, A. (1996). Mémoire de travail et langage dans le syndrome de Down. Doctoral thesis in Psychology (Logopedics), Université de Liège, Belgium (unpublished).

Dani, A., Pietrini, P., Furey, M., McIntosh, A., Grady, C., Horwitz, B., Freo, U., Alexander, G., \& Shapiro, M. (1996). Brain cognition in metabolism in Down syndrome adults in association with development of dementia. NeuroReport, 7, 2933-2936.

Das, J.-P., Divis, B., Alexander, J., Parrila, R., \& Naglieri, J. (1995). Cognitive decline due to aging among persons with Down syndrome. Research in Developmental Disabilities, 16, 461-478.

Deb, S., de Silva, N., Gemmel, H., Besson, J., Smith, F., \& Ebmeier, K. (1992). Alzheimer's disease in adults with Down syndrome: The relationship between the regional cerebral blood flow equivalents and dementia. Acta Psychiatrica Scandinavia, 86, 340-345.

Devenny, D., Hill, A., Patxot, O., Silverman, W., \& Wisniewski, H. (1992). Ageing in higher functioning adults with Down's syndrome: An interim report in a longitudi nal study. Journal of Intellectual Disability Research, 36, 241-250.

Devenny, D., Silverman, W., Hill, A., Jenkins, E., Sersen, E., \& Wisniewski, H. (1996). Normal ageing in adults with Down's syndrome: A longitudinal study. Journal of Intellectual Disability Research, 40, 208-221.

Dupont, A., Vaeth, M., \& Videbech, P. (1986). Mortality and life expectancy of Down's syndrome in Denmark. Journal of Mental Deficiency Research, 30, 111-120.

Evenhuis, H., Kengen, M., \& Eurlings, H. (1990). Dementia Questionnaire for Mentally Retarded Persons (DMR). Zwammerdam, Holland: Hooge Burch Center for People with Intellectual Disability.

Florez, J. (1993). El envejecimiento de las personas con sindrome de Down. Revista Sindrome de Down, 10, 55-62.

Florez, J. (2000). El envejecimiento de las personas con sindrome de Down. Revista Sindrome de Down, 17, 16-24.

Fowler, A. (1990). Language abilities in children with Down's syndrome: Evidence for a specific syntactic delay. In D. Cicchetti \& M. Beeghly (Eds.), Children with Down Syndrome: A Developmental Perspective (pp. 302-328). New York: Cambridge University Press.

Frostig, M., Maslow, P., Lefever, D., \& Whittlesy, J. (1963). The Marianne Frostig Developmental Test of Visual Perception. Palo Alto, CA: Counsulting Psychologist Press.

George, M., Thewis, B., Van der Linden, M., Salmon, E., \& Rondal, J.A. (1999). Langage et mémoire chez les sujets vieillissants porteurs d'un syndrome de Down. Etude longitudinale. Convention de Recherche entre le Fonds National de la Recherche Fondamentale et Collective de Belgique et l'Université de Liège, $\mathrm{N}_{\mathrm{i}}$ 2.4535.95F, Rapport final d'activité (4e. année), Liège, Université de Liège, Laboratoire de Psycholinguistique (unpublished).

George, M., Thewis, B., Van der Linden, M., Salmon, E., \& Rondal, J.A. (submitted for publication). Elaboration d'une batterie d'évaluation des fonctions cognitives de sujets âgés avec syndrome de Down.

Hart, A. (1988). Language and dementia: A review. Psychological Medicine, 18, 99-112.

Hoffman, J., Hamson, M., Welsh, K., Earl, N., Raine, S., Delong, D., \& Coleman, R. (1996). Interpretation variability of 18FDG-positron emission tomography studies in dementia. Investigation in Radiology, 31, 316-322.

Holland, A., \& Oliver, C. (1996). Down's syndrome and the links with Alzheimer's disease. Journal of Neurology, Neurosurgery, and Psychiatry, 59 (2), 111-114.

Hummel, T., \& Sligo, J. (1971). Empirical comparison of unvariate and multivariate analysis of variance procedures. Psychological Bulletin, 76, 49-57.

Jancar, J., \& Jancar, P. (1996). Longevity in Down syndrome: A twelve year survey (1984-1995). Italian Journal of Intellectual Impairment, 9, 27-30.

Jodar, M. (1992). Envejecimiento normal versus demencia de Alzheimer. Valor del lenguaje en el diagnostico differencial. Revista de Logopedia, Foniatria y Audiologia, 12, 171-179.

Kaufman, A., \& Kaufman, N. (1993). K-ABC, Batterie pour l'Examen Psychologique de l'Enfant. Paris: Editions du Centre de Psychologie Appliquée.

Kempler, D., Curtiss, S., \& Jackson, C. (1987). Syntactic preservation in Alzheimer's disease. Journal of Speech and Hearing Research, 30, 343-350.

Lenneberg, E. (1967). Biological Foundations of Language. New York: Wiley.

Lunney, G. (1970). Using analysis of variance with a dichotomous dependent variable: An empirical study. Journal of Educational Measurement, 7, 263-269.

Mann, D. (1992). The neuropathology of the amygdala in ageing and in dementia. In J. Aggleton (Ed.), The Amygdala: Neurobiological Aspects of Emotion, Memory, and Mental Dysfunction (pp. 575-593). New York: WileyLiss.

Martin, A. (1987). Representations of semantic and spatial knowledge in Alzheimer's patients: Implications for models of preserved learning and amnesia. Journal of Clinical and Experimental Neuropsychology, 9, 121-124.

Maxim, J., \& Bryan, K. (1994). Language of the Elderly: A Clinical Perspective. London: Whurr.

Murillo Ruiz, B. (1999). Estudio de la Evolucion del Lenguaje en la Demencia Alzeimer. Barcelona: ISEP Editorial. 
Péna-Casanova, J. (1990). Programa Integrado de Exploracion Neuropsicologica: Test Barcelona. Barcelona: Masson.

Pedrabissi, R., \& Soresi, S. (1989). Adattamento dell'ABI con oggetti RM di Diversa Gravità ed Eziologia. Trento, Italy: Erickson.

Pickut, B., Saerens, J., Marien, P., Borggreve, F., Goeman, J., Vandevivere, J., Vervaet, A., Diercks, R., \& de Keyn, P. (1997). Discrimination use of SPECT in frontal lobetype dementia versus (senile) dementia of the Alzheimer's type. Journal of Nuclear Medicine, 38, 929-934.

Prasher, V. (1996). Age-associated functional decline in adults with Down's syndrome. European Journal of Psychiatry, 10, 129-135.

Ribes, R., \& Sanuy, J. (2000). Declive cognitivo en memoria y lenguaje: indicadores del proceso de envejecimiento psicologico en la persona con sindrome de Down. Revista Sindrome de Down, 17, 54-59.

Rondal, J.A. (1995). Exceptional Language Development in Down Syndrome. Implications for the Cognition Language Relationship. New York: Cambridge University Press.

Rondal, J.A., \& Comblain, A. (1996). Language in adults with Down syndrome. Down Syndrome Research and Practice, 4 (1), 3-14.

Rondal, J.A., \& Edwards, S. (1997). Language in Mental Retardation. London: Whurr.

Royston, M., Mann, D., Pickering-Brown, S., \& Owen, F. (1994). Apolipoprotein E., e2 allele promotes longevity and protects patients with Down's syndrome from dementia. Neuro Report, 5, 2583-2585.

Saviolo-Negrin, N., Soresi, S., Baccichetti, C., Pozzan, G., \& Trevisan, E. (1990). Observations on the visual perceptual abilities and adaptive behavior in adults with Down syndrome. American Journal of Medical Genetics, Supplement, 7, 309-313.

Schapiro, M., Haxby, J., \& Grady, C. (1992). Nature of mental retardation and dementia in Down syndrome: Study with PET, CL, and neuropsychology. Neurobiology of Aging, 13, 723-734.

Schapiro, M., \& Haxby J., Grady, C., Duara, R., Schlageter, N., White, B., Moore, A., Sunadaram, M., Larson,S., \& Rapoport, S. (1987). Decline in cerebral glucose utilization and cognitive function with aging in Down's syndrome. Journal of Neurology, Neurosurgery, and Psychiatry, 50, 766-774.

Strauss, D., \& Eyman R. (1996) Mortality of people with mental retardation in California with and without Down syndrome, 1986-1991. American Journal of Mental Retardation, 100, 643-651.

Thompson, S. (1999). Examining dementia in Down's syndrome. Decline in social abilities in Down syndrome compared with other learning disabilities. Clinical Gerontologist, 20, 23-44.

Vicari, S., Nocentini, U., \& Caltagirone, C. (1994). Neuropsychological diagnosis of aging in adults with Down syndrome. Developmental Brain Dysfunction, 7 , 340-348.

Wilson, B., Ivani-Chalian, R. (1995). Performance of adults with Down's syndrome on the Children's version of the Rivermead Behavioural Memory Test. British Journal of Clinical Psychology, 34, 85-88.
Wilson, B., Ivani-Chalian, R., \& Aldrich, F. (1991). The Rivermead Behavioural Memory Test for Children Aged 5-10 years (RBMT-C); Manual. Bury St. Edmunds, UK: Thames Valley Test Company.

Wisniewski, H., \& Silverman, W. (1996). Alzheimer disease, neuropathology and dementia in Down syndrome. In J.A. Rondal, J. Perera, L. Nadel, \& A. Comblain (Eds.), Down Syndrome: Psychological, Psychobiological and SocioEducational Perspectives (pp. 43-52). London: Whurr.

Wisniewski, H., \& Silverman, W. (1999). Down syndrome and Alzheimer disease: Variability in individual vulnerability. In J.A. Rondal, J. Perera, \& L. Nadel (Eds.) Down Syndrome: A Review of Current Knowledge (pp. 178-194). London: Whurr.

Ylieff, M. (May 2000a). Evaluation neuropsychologique de Françoise (document confidentiel). Liège, Université de Liège, Service de Psychologie de la Santé, Unité de Psychologie Clinique du Vieillissement.

Ylieff, M. (May 2000b). Personal communication with J.A. Rondal.

Zigman, W., Schup, N. Haaveman, M., \& Silverman, W. (1997). The epidemiology of Alzheimer disease in intellectual disability: Results and recommendations from an international conference. Journal of Intellectual Disability Research, 41, 76-80. 